Revista Brasileira de Agricultura Irrigada v.12, nº.6, p. 2991 - 3001, 2018

ISSN 1982-7679 (On-line)

Fortaleza, CE, INOVAGRI - http://www.inovagri.org.br

DOI: $10.7127 /$ rbai.v12n600855

Protocolo 855.18 - 26/12/2017 Aprovado em 30/09/2018

\title{
EFEITO DE FERTILIZANTE E DIFERENTES TEMPOS DE IMERSÃO EM VINAGRE NA PRODUÇÃO DE MUDAS DE PINHEIRA (Annona squamosa L.)
}

Marinês Pereira Bomfim¹; Wellinghton Alves Guedes²; Camilo de Lellis de Sousa Almeida²

\section{RESUMO}

As sementes de anonáceas apresentam dormência que, por alguma razão ainda desconhecida, inibe a germinação após a secagem. Assim, procurando utilizar um método simples para superação dessa dormência objetivou-se avaliar o efeito do fertilizante organomineral Raiza ${ }^{\circledR}$ e diferentes tempos de imersão em vinagre de maçã na propagação de pinheira. O experimento foi conduzido em delineamento em blocos ao acaso, em esquema fatorial 5 x 4, com cinco concentrações de Raiza ${ }^{\circledR}$ $(0,5,10,15$ e $20 \%)$ e quatro tempos de imersão $(0,20,40$ e 60 minutos), em 4 repetições. As variáveis analisadas foram: número de folhas (NF), altura das plantas (AP), diâmetro do caule (DC), comprimento do sistema radicular (CR), massa seca da parte aérea (MSPA), massa seca da raiz (MSR), relação parte aérea/raiz (RPA/R), massa seca total (MST) e índice de qualidade de Dickson (IQD). Nas condições em que o presente trabalho foi desenvolvido conclui-se que o crescimento das mudas de pinheira foi influenciado pelo uso do Raiza®, demostrando que a concentração de $20 \%$ do fertilizante Raiza ${ }^{\circledR}$ apresenta os melhores resultados quando aplicado em sementes que não foram imersas em vinagre. Quando realizada a imersão das sementes em vinagre por 20 e 40 minutos em combinação com 5\%. do fertilizante Raiza. foram obtidos resultados superiores do fertilizante Raiza®.

Palavras-chave: Propagação, manejo, enraizamento, dormência.

\section{EFFECT OF FERTILIZER AND TIME OF SOAKING IN VINEGAR ON THE PRODUCTION OF SUGAR APPLE SEEDLINGS (Annona squamosa L.)}

\footnotetext{
ABSTRACT

The seeds of anonaceae present dormancy, for some reason still unknown, what inhibits the germination after drying. Thus, looking for a simple method to overcome this dormancy, the aim of this study was to verify the effect of the Raiza ${ }^{\circledR}$ fertilizer and different soaking times with apple

1 Dra. Profa. Visitante, Universidade Federal de Campina Grande (UFCG), Pombal, PB, Brasil. e-mail: mpbfito@gmail.com

${ }^{2}$ Mestre em Horticultura Tropical, Universidade Federal de Campina Grande (UFCG), Pombal, PB, Brasil. e-mail: wellinghton_guedes@hotmail.com
} 
vinegar on the sugar apple propagation. The experiment was carried out under a randomized block design ( 5 x 4 factorial scheme), with five concentrations of Raiza ${ }^{\circledR}(0,5,10,15$, and 20\%), four soaking times $(0,20,40$, and 60 minutes), and four replicates. The following variables were measured: number of leaves (NF), plant height (AP), stem diameter (DC), root system length (CR), shoot dry mass (MSPA), root dry mass (MSR), shoot/root ratio (RPA/R), total dry mass (MST), and the Dickson quality index (IQD). With the results obtained and under the conditions in which the present work was conducted, it is concluded that the $20 \%$ concentration of the Raiza ${ }^{\circledR}$ fertilizer presented the best results when applied to seeds that were not immersed in vinegar. When the seeds were soaked in vinegar for 20 and 40 minutes in combination with $5 \%$ of the Raiza ${ }^{\circledR}$ fertilizer high results where obtained for the variables plant height, stem diameter, root length, shoot dry weight and total dry mass.

Keywords: Propagation, management, rooting, dormancy.

\section{INTRODUÇÃO}

O território brasileiro é caracterizado por diferentes classificações climáticas e de solo, tornando-se numa zona de destaque para o cultivo de fruteiras, principalmente as tropicais e as subtropicais (SOUSA et al., 2008). Entre as tropicais destaca-se a pinheira (Annona squamosa L.), uma planta famosa pelo sabor e a qualidade nutricional dos frutos. A pinheira também conhecida como fruta-do-conde ou ata, é muito cultivada no Brasil, sendo os Estados da Bahia e Alagoas os maiores produtores (BRAGA SOBRINHO, 2014).

Esta cultura é propagada de forma sexuada, método considerado de grande importância, quando o interesse é a produção de mudas para porta-enxerto. A pinheira, quando utilizada como porta-enxerto, gera plantas compactas, ideais para a produção comercial de mudas enxertadas. Segundo Stenzel et al. (2003), o porta-enxerto de pinheira é recomendado para a realização da enxertia em atemóia, porém, a produção de mudas de pinheira via sementes esbarra em problemas como a dormência, que nesse caso acarreta problemas na fase de germinação e prejudicam uma maior disponibilidade de mudas de alta qualidade para a implantação de novas áreas cultivadas. Segundo Paiva et al. (2013), é muito importante a formação de mudas de qualidade, pois constitui uma etapa crucial no processo de produção, possibilitando aos agricultores a obtenção de plantas com elevado vigor e maior possibilidade de suportarem as condições adversas no campo.
Apesar da dormência das sementes de pinheira ser um fenômeno comprovado, ainda assim existem controvérsias sobre os fatores envolvidos em seus mecanismos (MORAIS et al., 2014). Sousa et al. (2008) sugerem duas hipóteses, a primeira devido à presença de um tegumento resistente e impermeável, que impede a embebição da semente e a oxigenação do embrião, que permanece latente e a segunda provocada por um desequilíbrio hormonal. Segundo Campos et al. (2015), o mecanismo de dormência é uma desvantagem por induzir grande desuniformidade entre as mudas e maior demanda de tempo de produção para os viveiristas e produtores.

Mendonça et al. (2007) indicam que mais estudos devem serem realizados para esclarecer o tipo de mecanismo envolvido na dormência das sementes de anonáceas, incluindo a pinheira, na busca de novas tecnologias para superação da dormência e que não ocorra comprometimento do vigor das mudas, permitindo assim maior longevidade e desenvolvimento vigoroso das plantas.

Neste sentido, a utilização do vinagre deve agir na superação do tegumento, aumentando a permeabilidade dos envoltórios e facilitando a germinação das sementes de pinheira. Segundo Ledo e Cabanelas (1997), estudando a superação da dormência de sementes de graviola (Annona muricata L.), verificaram que a imersão em vinagre por 15 minutos, foi significativamente superior quanto às taxas de germinação e velocidade de emergência em relação às sementes sem tratamento. Após a germinação, é importante a utilização de produtos que forneçam os 
nutrientes necessários para o desenvolvimento das mudas de pinheira. Uma adubação adequada e bem equilibrada, o produtor poderá se beneficiar da qualidade das mudas obtidas, do estado fitossanitário e do vigor das plantas, bem como da produtividade de seu pomar. Assim, o fertilizante organomineral Raiza ${ }^{\circledR}$ será o responsável por realizar a nutrição das mudas de pinheira e evitar possíveis deficiências nutricionais.

Em face ao exposto, objetivou-se avaliar a influência da utilização do vinagre de maçã na superação da dormência das sementes e a utilização do fertilizante organomineral Raiza ${ }^{\circledR}$ para a fase de produção de mudas de pinheira.

\section{MATERIAL E MÉTODOS}

O presente trabalho foi desenvolvido nas instalações da Universidade Federal de Campina Grande (UFCG), no Centro de Ciências e Tecnologia Agroalimentar (CCTA), campus Pombal-PB, em casa de vegetação, cujas coordenadas geográficas são: $6^{\circ} 46^{\prime} 13$ ' latitude $\mathrm{S}$ e $37^{\circ} 48^{\prime} 06^{\prime}$ ' longitude W de Greenwich e altitude de $184 \mathrm{~m}$. Durante a condução do experimento foram registradas, no interior da casa de vegetação, a temperatura (mínima: $22,6{ }^{\circ} \mathrm{C}$; média: $29,65^{\circ} \mathrm{C}$; máxima: $44,37^{\circ} \mathrm{C}$ ) e a umidade relativa do ar (mínima: 20\%; média: 32\%; máxima: $48,5 \%$ ) ao longo do experimento, com auxílio de um termohigrômetro.

O delineamento experimental utilizado foi o de blocos ao acaso (DBC), em esquema fatorial 5 x 4 (5 concentrações do fertilizante organomineral Raiza $^{\circledR}$ x 4 tempos de embebição das sementes no vinagre de maçã), com vinte tratamentos, quatro repetições e duas plantas por repetição. As concentrações do fertilizante Raiza ${ }^{\circledR}$ foram 0,5 , 10,15 e $20 \%$ e quatro tempos de embebição em vinagre de maçã ( 0 - testemunha-, 20,40 e 60 minutos).

O fertilizante organomineral Raiza ${ }^{\circledR}$ é composto por $4 \%$ de nitrogênio solúvel em água; $12,5 \%$ de carbono orgânico total em suspensão homogênea com densidade de 1,22 e índice salino de $12 \%$. Já o vinagre de maçã possui em sua composição fermentado acético de maçã e água, conservante: metabissulfito de sódio e acidez volátil de $4 \%$.
O substrato para produção das mudas foi constituído por terra, areia e estrume bovino curtido, na proporção 3:2:1. O substrato utilizado apresentava as seguintes características químicas: pH em água: 6,46; matéria orgânica: $21,20 \mathrm{~g} \mathrm{~kg}^{-1}$; P: 2,40 mg L-1 $\mathrm{Ca}^{2+}$ : 9,07 $\mathrm{cmol}_{\mathrm{c}} \mathrm{kg}^{-1} ; \mathrm{Na}^{+}: 0,10$ cmolc $\mathrm{kg}^{-1} ; \mathrm{K}: 1,52 \mathrm{mg} \mathrm{dm}^{-3}$; SB:13,24 $\mathrm{cmolc} \mathrm{kg}^{-1}$; CTC: $14,76 \mathrm{cmol}_{\mathrm{c} \mathrm{kg}}{ }^{-1}$; V: 89,70\%; PST: 0,68\%.

As sementes de pinheira foram adquiridas em um pomar comercial, localizado em Wenceslau Guimarães-BA. A sementeira foi realizada colocando duas sementes por saco de polietileno com dimensões de 16 × $22 \mathrm{~cm}$ na profundidade de $2 \mathrm{~cm}$. Aos 30 dias após a emergência, foi efetuado o desbaste, deixando uma muda por recipiente. As irrigações foram realizadas uma vez ao dia de modo a deixar o substrato próximo à capacidade de campo, com base no método de pesagem repondo a água evaporada, lixiviada ou absorvida pelas mudas. $\mathrm{O}$ fertilizante organomineral Raiza ${ }^{\circledR}$ foi aplicado via solo sendo realizada a primeira aplicação no mesmo dia em que foi realizada a sementeira e persistiram durante a condução do experimento, sendo aplicado semanalmente de acordo com as concentrações em estudo.

Aos 75 dias após a sementeira avaliaram-se as seguintes variáveis: número de folhas (NF), altura das plantas (AP) em cm, diâmetro do caule (DC) em mm, comprimento da raiz (CR) em cm, massa seca da parte aérea (MSPA), massa seca da raiz (MSR) e massa seca total (MST) em $\mathrm{g}$, relação massa seca da parte aérea/raiz (RPA/R) e índice de qualidade de Dickson (IQD) através da fórmula descrita na equação 1 .

$$
\mathrm{IQD}=\frac{\mathrm{MST}}{(A P \mid D C)+(M S P A \mid M S R)}
$$

Os dados foram submetidos à análise de variância pelo teste $\mathrm{F}$ ( 1 e $5 \%$ de probabilidade) e, nos casos de efeito significativo, realizou-se análise de regressão, utilizando-se o software estatístico SISVAR (FERREIRA, 2011). A escolha da regressão foi mediante melhor ajuste em base do coeficiente de determinação $\left(\mathrm{R}^{2}\right)$ e levando-se em consideração uma provável explicação biológica. 


\section{RESULTADOS E DISCUSSÃO}

De acordo com os dados de crescimento pode-se observar que houve interações significativas entre as concentrações do fertilizante Raiza ${ }^{\circledR}$ e os tempos de imersão das sementes para todas as variáveis analisadas, que foram influenciadas significativamente ao nível de $1 \%$ de probabilidade (Tabela 1 ).

Tabela 1. Resumo da análise de variância das variáveis número de folhas (NF), altura de plantas (AP), diâmetro do caule (DC), comprimento da raiz (CR), massa seca da parte aérea (MSPA), relação parte aérea/raiz (RPA/R), massa seca total (MST) e Índice de Qualidade de Dickson (IQD) em mudas de pinheira aos 75 dias após a sementeira.

\begin{tabular}{ccccccccccc}
\hline \multirow{2}{*}{ FV } & \multirow{2}{*}{ GL } & \multicolumn{10}{c}{ Quadrado Médio } \\
\cline { 2 - 10 } & & NF & AP & DC & CR & MSPA & MSR & RPA/R & MST & IQD \\
\hline Raiza $(\mathrm{R})$ & 4 & $28,47^{* *}$ & $40,79^{* *}$ & $0,75^{* *}$ & $17,94^{*}$ & $0,28^{* *}$ & $0,020^{* *}$ & $1,78^{\text {ns }}$ & $0,46^{* *}$ & $0,72^{\text {ns }}$ \\
Tempo (T) & 3 & $12,85^{* *}$ & $11,00^{\text {ns }}$ & $0,37^{* *}$ & $14,34^{\text {ns }}$ & $0,13^{\text {ns }}$ & $0,009^{\text {ns }}$ & $3,25^{\text {ns }}$ & $0,17^{\text {ns }}$ & $7,13^{* *}$ \\
T x R & 12 & $25,46^{* *}$ & $46,21^{* *}$ & $0,45^{* *}$ & $36,33^{* *}$ & $0,28^{* *}$ & $0,017^{* *}$ & $5,08^{* *}$ & $0,41^{* *}$ & $6,16^{* *}$ \\
Erro & 57 & 2,74 & 9,03 & 0,07 & 6,42 & 0,05 & 0,004 & 1,58 & 0,08 & 1,13 \\
\hline CV $(\%)$ & - & 15,07 & 20,47 & 8,35 & 23,16 & 33,86 & 34,81 & 33,71 & 32,35 & 26,15 \\
\hline
\end{tabular}

** significativo a $1 \%$; * significativo a $5 \% ;{ }^{\text {ns }}$ não significativo, pelo teste $\mathrm{F}$; $\mathrm{CV}$ - coeficiente de variação

O número de folhas por planta apresentou um comportamento quadrático em relação ao tempo de imersão e concentrações de Raiza ${ }^{\circledR}$ (Figura 1). Verifica-se um incremento de $35,1 \%$ no número de folhas quando aplicado a maior concentração do Raiza ${ }^{\circledR}(20 \%)$ em relação à testemunha. Para o tempo de imersão de 20 minutos e concentração do Raiza ${ }^{\circledR}$ de $10 \%$ observou-se NF de 11,98. Para o tempo de 40 minutos e concentração de $15 \%$ Raiza ${ }^{\circledR}$ obteve-se
NF de 10,93 e o tempo de 60 minutos e concentração de $10 \%$ Raiza ${ }^{\circledR}$ proporcionou aumento de 14,11. Estes resultados indicaram que a imersão das sementes por um período prolongado no vinagre, seguido de aplicações do fertilizante Raiza ${ }^{\circledR}$ influenciaram de forma positiva no aumento do número de folhas das mudas de pinheira.

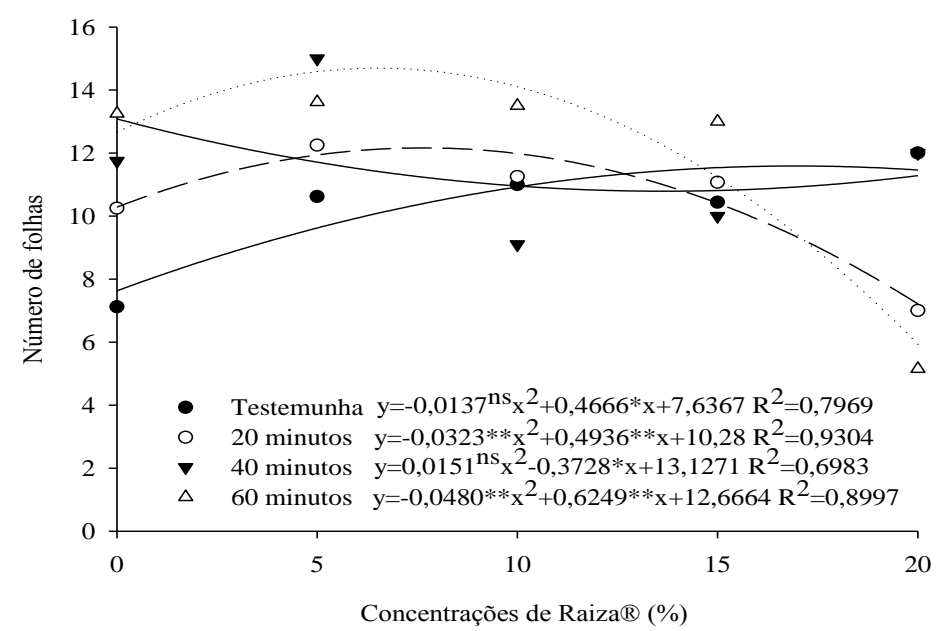

Figura 1. Número de folhas (NF) de pinheira em função do tempo de embebição das sementes em vinagre e diferentes concentrações de Raiza ${ }^{\circledR}$ aos 75 dias após a sementeira.

Guimarães et al. (2012), estudando a utilização de diferentes concentrações do fertilizante Raiza ${ }^{\circledR}$ no crescimento de mudas de mamoeiro, verificaram a ocorrência de incremento no crescimento das plantas em resposta ao aumento da concentração do fertilizante até $1,8 \%$, alcançando maior número de folhas $(5,22)$. De acordo com Cavalcanti Júnior (2001), a superação da dormência em sementes de graviola foi obtida na imersão em vinagre por 15 minutos, 
favorecendo assim a percentagem de emergência e índice de velocidade de emergência, que foram de $48,78 \%$ e 0,47 , respectivamente. A altura de plantas apresentou um comportamento linear em relação ao tempo 0 de imersão (testemunha) e concentrações de Raiza®. Nas mudas de pinheira que receberam as concentrações do fertilizante Raiza ${ }^{\circledR}$, e não foram imersas em vinagre, verificou-se um acréscimo linear da altura de plantas de 38,1\% em relação à testemunha

(Figura2).

(0\% do fertilizante Raiza®) ocorreram devido à presença do tegumento das sementes serem resistentes, permitindo a hidratação das sementes lentamente após a sementeira, assim as maiores concentrações do Raiza ${ }^{\circledR}$ não chegaram a causar toxicidade no início do processo germinativo.

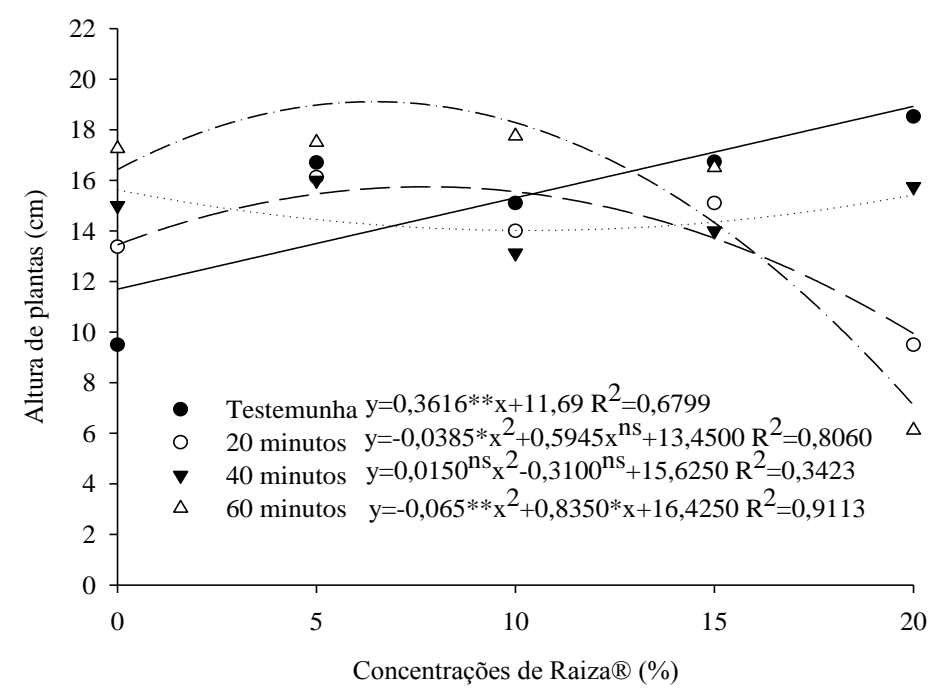

Figura 2. Altura de plantas (AP) de pinheira em função do tempo de embebição das sementes em vinagre e diferentes concentrações de Raiza ${ }^{\circledR}$ aos 75 dias após a sementeira.

Porém, este fenômeno foi contrário aos tratamentos em que as sementes foram imersas em vinagre, nos tempos de 20, 40 e 60 minutos, onde apresentou um comportamento quadrático nos diferentes tempos de imersão e concentrações do Raiza®. Sendo observada uma resposta positiva de 15,$54 ; 21,31$ e $18,97 \mathrm{~cm}$ para as concentrações 10,20 e $5 \%$, respectivamente. O vinagre de maçã possui na sua constituição ácido acético, assim, este ácido possivelmente reduz a barreira biológica presente nas sementes de pinheira.

Constata-se que a utilização de concentrações elevadas do fertilizante Raiza®, aliada a longos períodos de imersão das sementes em vinagre causou toxicidade e afetou o crescimento das mudas. Segundo Guimarães et al. (2012), estudando a aplicação de diferentes concentrações do fertilizante Raiza ${ }^{\circledR}$ no crescimento de mudas de mamoeiro verificaram um incremento na altura das mudas em função das concentrações do fertilizante Raiza ${ }^{\circledR}$, sendo verificada uma altura de 5,8 a $9,7 \mathrm{~cm}$ e constatado um acréscimo de $1,96 \mathrm{~cm}$ nas mudas, quando utilizada até $2 \%$ Raiza®.

Para a variável diâmetro do caule, houve efeito significativo para a interação entre tempo de imersão e concentrações de Raiza®.

A equação o quadrática foi a que melhor se ajustou aos dados relacionados ao diâmetro do caule, constatando-se com incremento das concentrações do Raiza®. $\mathrm{O}$ aumento do tempo de imersão das sementes de pinheira favoreceu um efeito nocivo do fertilizante Raiza ${ }^{\circledR}$ as mudas, causando decréscimo (Figura 3). 


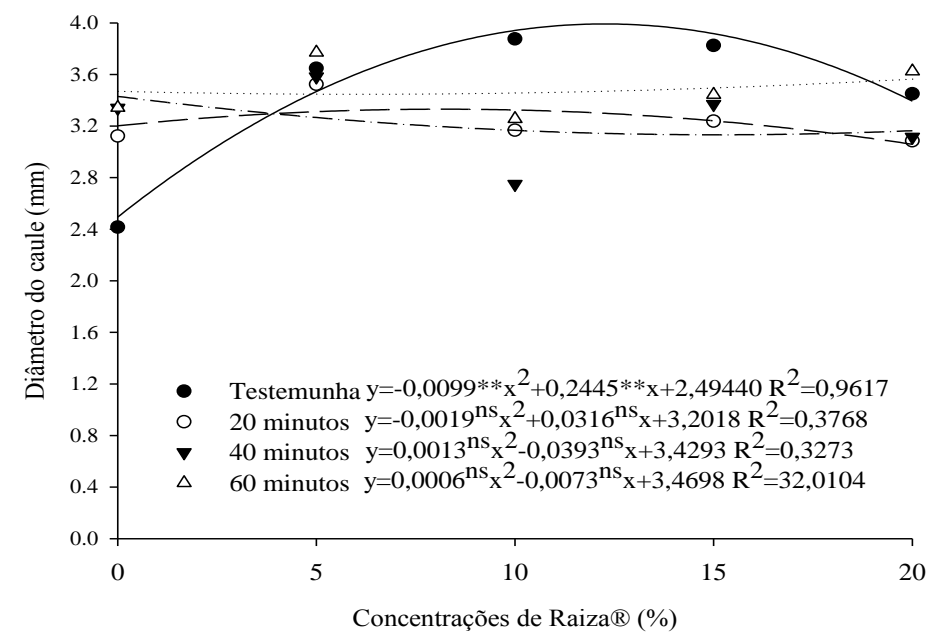

Figura 3. Diâmetro do caule (DC) de pinheira em função do tempo de embebição das sementes em vinagre e diferentes concentrações de Raiza ${ }^{\circledR}$ aos 75 dias após a sementeira.

Obteve-se diâmetro do caule de 3,94 e 3,32 mm para os tempos 0 (testemunha) e 20 minutos mais a concentração de $10 \%$ do Raiza®. Para o tempo de 40 minutos e concentração de $5 \%$ Raiza ${ }^{\circledR}$ obteve-se diâmetro de $3,26 \mathrm{~mm}$, e o tempo de 60 minutos e concentração de $20 \%$ Raiza® proporcionou aumento do diâmetro do caule de 3,56 mm. Possivelmente, a concentração de $20 \%$ causou toxidez às mudas, desta forma interferindo no crescimento das mudas de pinheira.

Segundo Dantas et al. (2012), ao avaliar a influência do ácido giberélico e do bioestimulante Stimulate ${ }^{\circledR}$ em mudas de tamarindo, relatou que reguladores de crescimento podem ter efeitos distintos sobre diferentes órgãos das plantas. Podendo desta forma explicar o fenômeno ocorrido nesta variável. Freitas et al. (2013) avaliando a influência de fertilizante fosfatado no desenvolvimento inicial de mudas de pinheira observaram que aplicações crescentes de Cosmofert® reduziu o diâmetro do colo das mudas de pinheira em $6,20 \mathrm{~mm}$ obtido na ausência do fertilizante aos 170 dias.

A variável comprimento do sistema radicular apresentou um comportamento linear em relação ao tempo 0 de imersão (testemunha) e concentrações de Raiza®. Observa-se que 14,07 $\mathrm{cm}$ para o tempo 0 (testemunha), quando utilizado $20 \%$ do Raiza ${ }^{\circledR}$. Para os demais tratamentos houve um comportamento quadrático nos diferentes tempos de imersão e concentrações de Raiza ${ }^{\circledR}$. Quando as sementes foram imersas por 20 minutos em vinagre, foi constatado que a concentração de $10 \%$ do Raiza ${ }^{\circledR}$ proporcionou um crescimento de $12,83 \mathrm{~cm}$ do sistema radicular. Já para o tempo de 40 e 60 minutos, observou que as menores concentrações do Raiza ${ }^{\circledR}$ proporcionou maior crescimento do sistema radicular, sendo de 12,53 e 14,01 cm, respectivamente (Figura 4). 


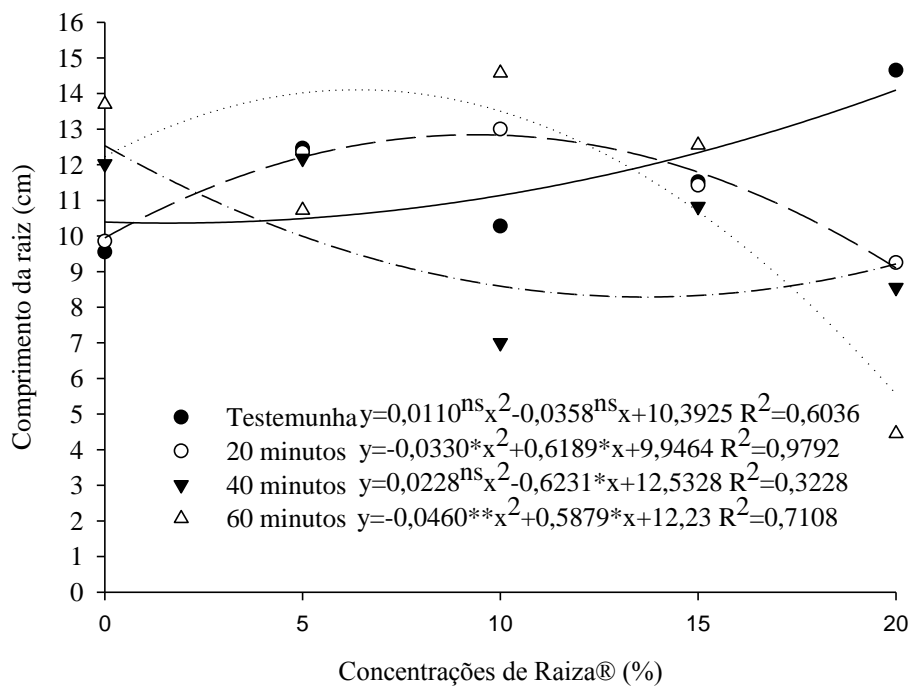

Figura 4. Comprimento da raiz (CR) de pinheira em função do tempo de embebição das sementes em vinagre e diferentes concentrações de Raiza ${ }^{\circledR}$ aos 75 dias após a sementeira.

Possivelmente, o tempo de 60 minutos que as sementes passaram tratadas via imersão em vinagre, permitiu uma maior permeabilidade do tegumento, de forma a permitir a embebição e a aceleração do início do processo germinativo. Constata-se que a utilização do Raiza ${ }^{\circledR}$ deve ser realizada em menores concentrações, quando for utilizado o método de imersão das sementes de pinheira em vinagre por 60 minutos. Segundo Guimarães et al. (2012), fertilizantes organominerais a base de extratos de algas como o Raiza®, são complexos que promovem o equilíbrio hormonal nas plantas, favorecendo a expressão do seu potencial genético e estimulando o desenvolvimento radicular.
Para a variável massa seca da parte aérea apresentou um comportamento quadrático em relação ao tempo de imersão e concentrações de Raiza ${ }^{\circledR}$. Verificou-se que as sementes que não foram imersas em vinagre, obtiveram um acúmulo de fitomassa de $0,5 \mathrm{~g}$, em relação à concentração de $20 \%$ do fertilizante Raiza ${ }^{\circledR}$ ao comparar com a testemunha $(0 \%)$. No entanto, sementes imersas em vinagre por 20,40 e 60 minutos, e que receberam $5 \%$ do fertilizante Raiza ${ }^{\circledR}$ obtiveram o maior acúmulo de fitomassa. Porém, a concentração de $20 \%$ do fertilizante Raiza ${ }^{\circledR}$ proporcionou um decréscimo nas mudas que foram embebidas em vinagre (Figura

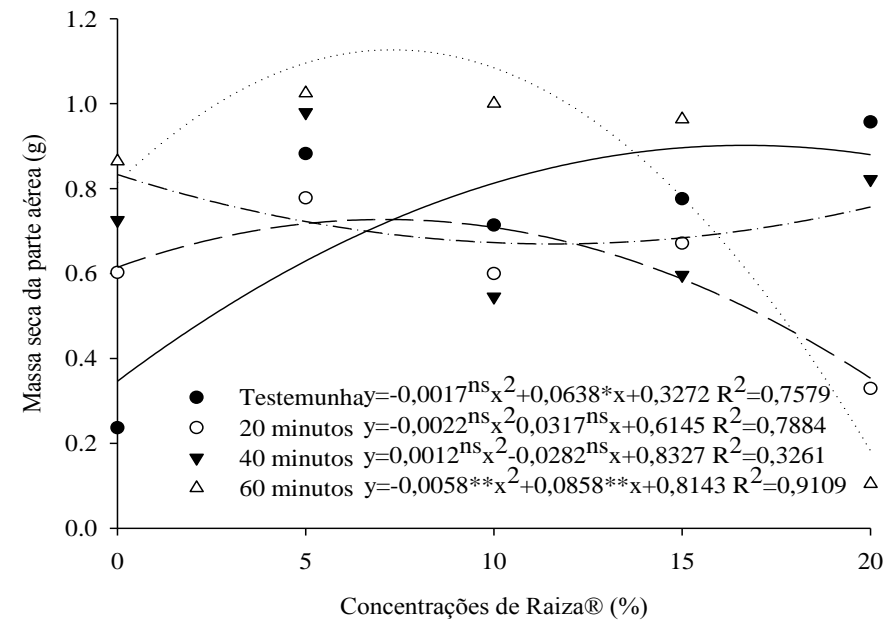

Figura 5. Massa seca da parte aérea (MSPA) de pinheira em função do tempo de embebição das sementes em vinagre e diferentes concentrações de Raiza ${ }^{\circledR}$ aos 75 dias após a sementeira. 
Para a massa seca da raiz houve um comportamento quadrático em relação ao tempo de imersão e concentrações de Raiza ${ }^{\circledR}$. Observouse que o tempo 0 (testemunha) e concentração de $15 \%$ de Raiza ${ }^{\circledR}$ proporcionou um crescimento de $0,21 \mathrm{~g}$ de massa seca do sistema radicular. Já para as sementes imersas por 20 e 60 minutos constata- se que a melhor concentração foi $10 \%$ do fertilizante Raiza ${ }^{\circledR}$, proporcionando um acúmulo de MSR de 0,22 e 0,32 g, respectivamente. Mas, no tempo de 40 minutos observou-se que a testemunha proporcionou maior acúmulo de MSR (0,25 g) (Figura 6).

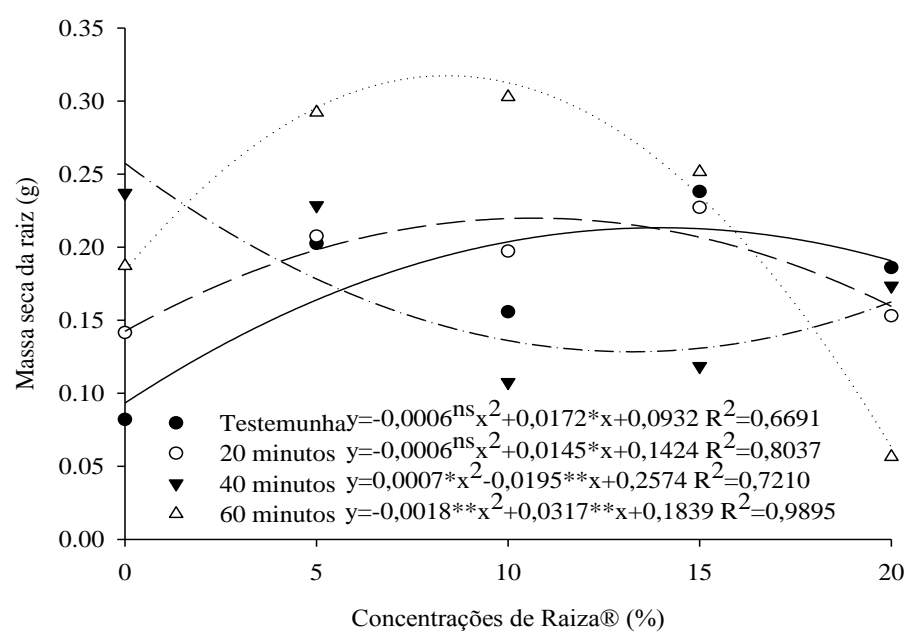

Figura 6. Massa seca da raiz (MSR) de pinheira em função do tempo de embebição das sementes em vinagre e diferentes concentrações de Raiza ${ }^{\circledR}$ aos 75 dias após a sementeira.

As mudas provenientes de sementes imersas em vinagre nos tempos de 20 e 60 minutos e utilizando concentrações superiores a $10 \%$ do fertilizante Raiza®, houve um decréscimo acentuado no acúmulo de massa seca da raiz. O crescimento das mudas não ocorreu devido à toxidez causada pelas maiores concentrações do Raiza®. Assim, prejudicou o crescimento inicial das mudas de pinheira, que baseia-se na elongação das células do meristema intercalar, que ao aumentar de tamanho, promovem a divisão celular. Deste modo, as maiores taxas de crescimento são observadas pelo aumento na formação de novas células e pela maior elongação celular em resposta à giberelina (SAUTER e KENDE, 1992; CAMPOS et al., 2015).

Andrade et al. (2015) avaliando a influência da aplicação de fertilizante orgânico em plantas de pinheira em função de substratos orgânicos obteve valores médios superiores, com massa seca da raiz com 2,5 a $3 \mathrm{~g}$ mais que no presente ensaio.

Para a relação parte aérea/raiz observou-se um comportamento linear em relação ao tempo 0 de imersão (testemunha) e concentrações de Raiza ${ }^{\circledR}$. Foi constatado que o tempo 0 (testemunha), mais $20 \%$ de Raiza ${ }^{\circledR}$ proporcionou uma relação de 5,24. Nos demais tempos de imersão observou um comportamento quadrático em relação as concentrações do Raiza ${ }^{\circledR}$. Para os tempos de 20 e 60 minutos na concentração $0 \%$ de Raiza ${ }^{\circledR}$ observou-se uma relação de 4,57 e 4,65, respectivamente (Figura 7). Resultados diferentes foram obtidos por Freitas et al. (2013), estudando a utilização do fertilizante organomineral Cosmofert $\AA$, onde constatou-se com o aumento das dosagens do fertilizante Cosmofert®, houve um incremento na relação parte aérea/raiz. 


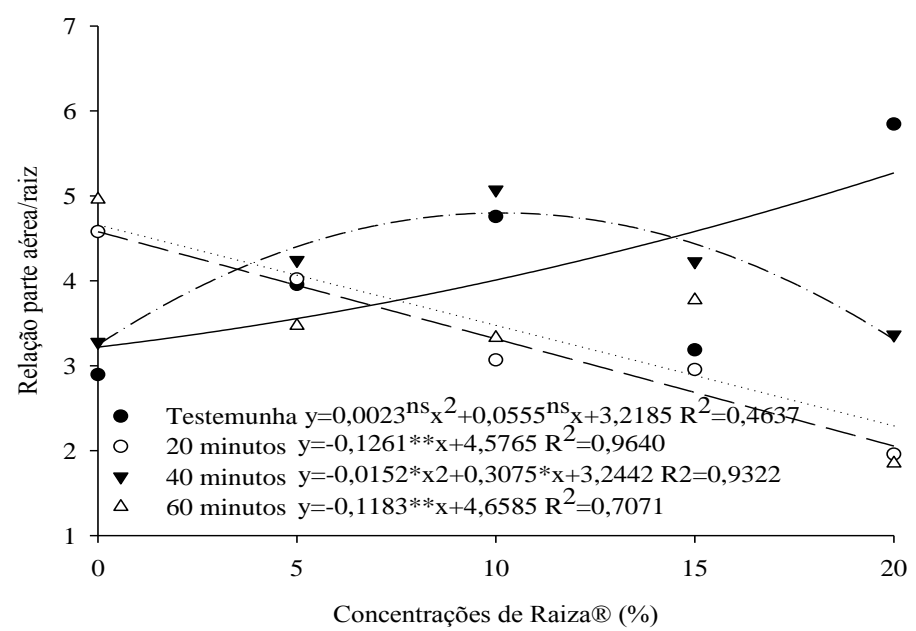

Figura 7. Relação parte aérea/raiz (RPA/R) de pinheira em função do tempo de embebição das sementes em vinagre e diferentes concentrações de Raiza ${ }^{\circledR}$ aos 75 dias após a sementeira.

Para a massa seca total observou-se um comportamento linear em relação ao tempo 0 de imersão (testemunha) e concentrações de Raiza®. Constatou um acúmulo de $1,21 \mathrm{~g}$ para o tempo 0 (testemunha) mais $20 \%$ de Raiza®. Para os demais tempos de imersão observou um comportamento quadrático em relação as concentrações de Raiza ${ }^{\circledR}$. Onde, sementes imersas por 20 e 40 minutos em vinagre, utilizando mais $5 \%$ de Raiza ${ }^{\circledR}$ constatou-se um acúmulo de MST de 1,91 e $1,09 \mathrm{~g}$, respectivamente. As sementes imersas por 60 minutos em vinagre, e que não foram aplicados Raiza ${ }^{\circledR}$ (testemunha) verificou-se um acúmulo de MST de 0,99 g (Figura 8).

Wagner Júnior et al. (2006) avaliando a influência de diferentes substratos na formação de mudas de pinheira obtiveram resultados médios variando de 0,06 a $0,71 \mathrm{~g}$ para massa seca total. Sendo inferior aos resultados obtidos nesta pesquisa quando foi utilizado $20 \%$ do Raiza®, no tempo 0 (testemunha).

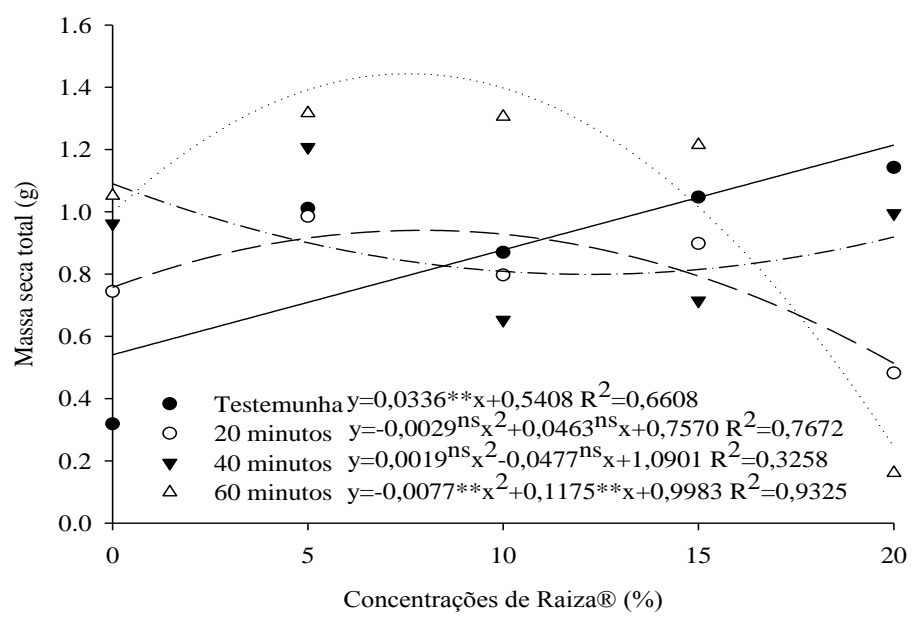

Figura 8. Massa seca total (MST) de pinheira em função do tempo de embebição das sementes em vinagre e diferentes concentrações de Raiza ${ }^{\circledR}$ aos 75 dias após a sementeira.

Para o índice de qualidade de Dickson observou-se um comportamento linear em relação ao tempo 0 de imersão (testemunha) e concentrações de Raiza®. As sementes que receberam $20 \%$ do fertilizante Raiza ${ }^{\circledR}$ foi obtido um IQD de 5,4. Observou-se um acréscimo de $38,7 \%$ em relação a testemunha $\left(0 \%\right.$ de Raiza $\left.{ }^{\circledR}\right)$. As sementes imersas em vinagre durante 40 
minutos apresentaram efeito quadrático, conforme foi aumentando as concentrações até $15 \%$ de fertilizante Raiza ${ }^{\circledR}$. A utilização da concentração de $20 \%$ do fertilizante Raiza ${ }^{\circledR}$ proporcionou um decréscimo de 0,57 ao comparar com o tratamento a $15 \%$ do fertilizante Raiza®, que proporcionou uma muda mais perfeita (Figura 9). O IQD é considerado como um bom indicador da qualidade das mudas por considerar para o seu cálculo o vigor, o equilíbrio da distribuição da biomassa, e algumas características de crescimento das mudas (FREITAS et al., 2013).

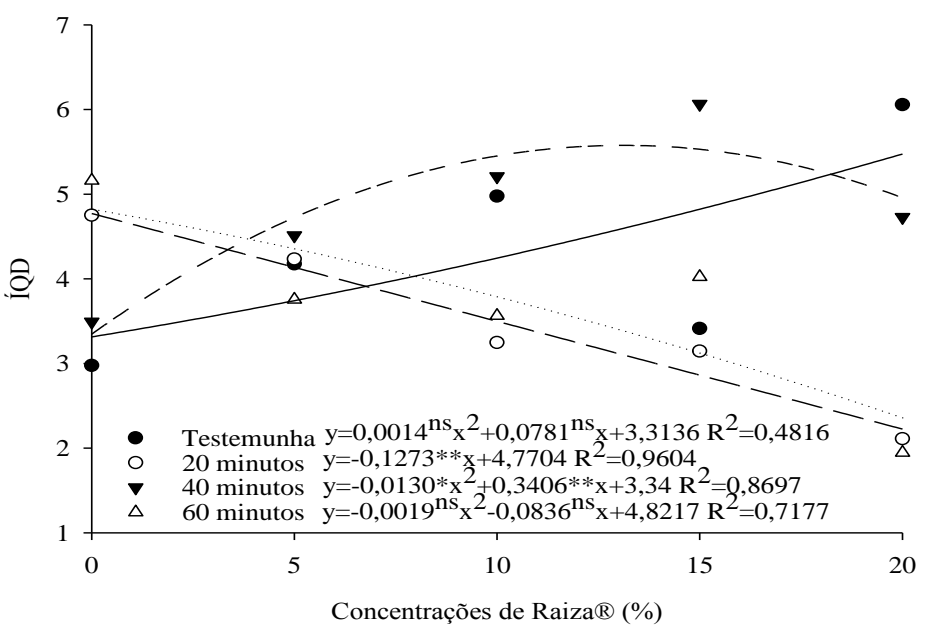

Figura 9. Índice de qualidade de Dickson (IQD) de pinheira em função do tempo de embebição das sementes em vinagre e diferentes concentrações de Raiza ${ }^{\circledR}$ aos 75 dias após a sementeira.

\section{CONCLUSÕES}

Nas condições em que o presente trabalho foi desenvolvido conclui-se que o crescimento das mudas de pinheira foi influenciado pelo uso do Raiza®, demostrando que a concentração de $20 \%$ do fertilizante Raiza ${ }^{\circledR}$ apresentou os melhores resultados quando aplicado em sementes que não foram imersas em vinagre.

Quando se procedeu à imersão das sementes em vinagre por 20 e 40 minutos recomenda-se a aplicação de $5 \%$ do fertilizante Raiza ${ }^{\circledR}$ para as variáveis altura de planta, diâmetro do caule, comprimento da raiz, massa seca da parte aérea e massa seca total.

\section{REFERÊNCIAS BIBLIOGRÁFICAS}

ANDRADE, A. F.; VÉRAS, M. L. M.; ARAÚJO, D. L.; MELO FILHO, J. S.; ANDRADE, R. Aplicação de fertilizante orgânico em plantas de pinha (Annona squamosa L.) em função de substratos orgânicos. Revista Terceiro Incluído, v. 5, n. 2, p. 141-154, 2015. https://doi.org/10.5216/teri.v5i2.38743
BRAGA SOBRINHO, R. Produção integrada de Anonáceas no Brasil. Revista Brasileira de Fruticultura, v. 36, n.1, p.102-107, 2014. http://dx.doi.org/10.1590/S0100-

29452014000500012

CAMPOS, L. F. C.; ABREU, C. M.; GUIMARÃES, R. N.; SELEGUINI, G. A. Escarificação e ácido giberélico na emergência e crescimento de plântulas de biribá. Ciência Rural, v. 45, n.10, p.1748-1754, 2015. http://dx.doi.org/10.1590/0103-8478cr20140249

CAVALCANTI JÚNIOR, A. T.; COSTA, A. M. G.; CORREIA, D. Superação da dormência de sementes de gravioleira (Annona muricata L.). Embrapa Agroindústria Tropical, 2001. 4 p. Embrapa Agroindústria Tropical. Comunicado técnico.

DANTAS, A. C. V. L.; QUEIROZ, J. M. O.; VIEIRA, E. L.; ALMEIDA, V. O. Effect of gibberellic acid and the biostimulant stimulate ${ }^{\circledR}$ on the initial growth of tamarind. Revista Brasileira de Fruticultura, v. 34, n. 1, p. 08-014, 2012. http://dx.doi.org/10.1590/S010029452012000100004 
FERREIRA, D. F. Sisvar: um sistema computacional de análise estatística. Ciência e Agrotecnologia, v. 35, n. 6, p. 1039-1042, 2011. http://dx.doi.org/10.1590/S1413$\underline{70542011000600001}$

FREITAS, R. M. O.; NOGUEIRA, N. W. PINTO, J. R. S.; TOSTA, M. S.; DOMBROSKI, J. L. D. Fertilizante fosfatado no desenvolvimento inicial de mudas de pinheira. Bioscience Journal, v. 29, n. 2, p. 319-327, 2013.

FERREIRA, G.; ERIG, P. R.; MORO, E. Uso de ácido giberélico em sementes de frutado-conde (Annona squamosa L.) visando à produção de mudas em diferentes embalagens. Revista Brasileira de Fruticultura, v. 24, n. 1, p. 178-182, 2002. http://dx.doi.org/10.1590/S0100-

$\underline{29452002000100039}$

GUIMARÃES, I. P.; BENEDITO, C. P.; CARDOSO, E. A.; PEREIRA, F. E. C. B.; OLIVEIRA, D. M. Avaliação do efeito do uso do extrato de alga (Raiza (®) no desenvolvimento de mudas de mamão. Enciclopédia Biosfera, v. $8, \quad$ n. $15, \quad$ p. 312-3019, 2012.

LEDO, A. S.; CABANELAS, C. I. L. Superação de dormência de sementes de graviola (Annona muricata L.). Revista Brasileira de Fruticultura, v. 19, n. 3, p. 397-400, 1997.

MENDONÇA, V.; RAMOS, J. D.; PIO, R.; GONTIJO, T. C. A.; TOSTA, M. S. Superação de dormência e profundidade de semeadura de sementes de gravioleira. Revista Caatinga, v. 20, n. 2, p. 73-78, 2007.

MORAIS, O. M.; OLIVEIRA, R. H.; OLIVEIRA, S. L.; SANTOS, V. B.; SILVA, J. C. G. Armazenamento de sementes de Annona squamosa L. Revista Biotemas, v. 22, n. 4, p. 33-
44, 2009. https://doi.org/10.5007/2175$\underline{7925.2009 v 22 \mathrm{n} 4 \mathrm{p} 33}$

PAIVA, J. R. G.; SILVA, F.; FERREIRA, L. L.; MESQUITA, E. F.; PORTO, V. C. N. Produção de mudas de pinheira (Annona Squamosa L.) em função da adubação orgânica e volumes de substrato. Cadernos de Agroecologia, v8, n. 2, 2013.

SÁ, F. V. S.; BRITO, M. E. B.; FERREIRA, I. B.; ANTÔNIO NETO P.; SILVA, L. A.; COSTA, F. B. Balanço de sais e c rescimento inicial de mudas de pinheira (Annona squamosa L.) sob substratos irrigados com água salina. Irriga, v. 20 , n. 3, p. 544-556, 2015.

https://doi.org/10.15809/irriga.2015v20n3p544

SAUTER, M.; KENDE, H. Gibberellin- induced growth and regulation of the cell division cycle in deepwater rice. Planta, v. 188, n. 3, p.362-368, 1992. 10.1007/BF00192803

STENZEL, N. M. C.; MURATA, I. M.; NEVES, C. S. V. J. Superação da dormência em sementes de atemóia e fruta-do-conde. Revista Brasileira de Fruticultura, v.25, n.2, p.305-308, 2003. http://dx.doi.org/10.1590/S0100-

$\underline{29452003000200031}$

SOUSA, S. A.; DANTAS, A. C. V. L.; PELACANI, C. R.; VIEIRA, E. L.; LEDO, C. A. S. Superação da dormência em sementes de pinha. Revista Caatinga, v. 21, n. 2, p. 139-146, 2008.

WAGNER JÚNIOR, A.; PIMENTEL, L. D.; NEGREIROS, J. R. S.; NERES, C. R. L.; ALEXANDRE, R. S.; DINIZ, E. R.; BRUCKNER, C. H. Influência do tempo de embebição em água sobre a dormência de sementes de pinha (Annona squamosa L.). Revista Ceres, v. 53, n. 307, p. 317-320, 2006. 